\title{
Teaching Narrative Text in Junior High School: Digital Story Telling in English as a Foreign Language (EFL) Context
}

\author{
Mutiara Shasqia \\ Universitas Lancang Kuning, Pekanbaru, Indonesia \\ mutiarashasqianew23@gmail.com
}

\author{
Received : 2019-11-11 \\ Revised :2020-03-04 \\ Accepted : 2020-03-24

\section{KEYWORDS} \\ Teaching Media \\ Digital Storytelling \\ Writing Skill \\ Narrative Text
}

ARTICLE HISTORY

\begin{abstract}
Current learning perspective is a process of giving learners to have the ability or skills in an innovative learning situation. In learning English, it requires techniques and creative so that learners have competence in writing narrative text. This research aims at proving digital storytelling can improve the junior high school students' writing skill in making narrative text. Digital storytelling is one of the media for teaching writing narrative text. The objectives of this qualitative study are to discuss the technique of teaching digital storytelling in writing process based on the selected literature and current study regarding the use of digital storytelling. This ongoing research tries to give an additional perspective and motivation to improve students' writing skill in the narrative text through digital storytelling. This study reveals that by using digital storytelling, the students can mastery some aspect in English.
\end{abstract}

\section{Introduction}

Learning is a process to acquire knowledge. It needs hard work and sometimes will make students frustrated and get bored so that they lose their attention to a lesson. In this study, the use of media in the teaching-learning process is needed to attract students' attention and to make teaching-learning activities more interesting and also effective. The use of media in the teaching-learning process is not a new thing. Many teachers know that media will be helpful. Media give students something new. Many media that we use in the learning process. In this era, with the sophistication of information and communication technology, the teacher should be creative for teaching because the media that used not only manual media but also online media. By teacher can be creative to create teaching media for the subject that they teach. This study use digital storytelling in teaching narrative text. Many students feel bored when they read the text narrative and also writing narrative text without media, and they feel hard to imagine about the story. By using digital storytelling, they directly see animation and story and the students are motivated to write narrative text by using three generic structures and directly can be a difference of 3 generic structures of narrative text.

\section{Literature Review}

Media is the communication outlets or tools used to store and deliver information or data. It is associated with the mass media communication businesses such as print media, the press, photography, advertising, cinema, broadcasting (radio and television), and publishing. Media inevitably, any course using these materials will be about much more than writing. Media of course, but I've clumped the MEF media clips into thematic units so the course can focus on four large topics that transcend issues of media: consumerism; gender and sexuality; race and class; media and politics. This way, students will develop important insights into these significant issues themselves — not just "the media." Note also that it doesn't make sense to contrast writing and the media. Writing itself is one of our most powerful and pervasive media. Lots of useful insights will emerge from discussions that compare the "old" medium of writing and the newer electronic media. For instance, what do the new media foster that "old writing" finds difficult and what does writing foster that the electronic media find difficult? Finally, there's a more significant topic that these materials inevitably address: a topic that transcends.

Writing has been with us for several thousand years and nowadays is more important than ever. Having spread steadily over the centuries from clay tablets to computer chips, it is poised for further dramatic advances. Although hundreds of millions of people are still unable to read and write, humanity relies on writing to an unprecedented extent. It is quite possible that today, more communication takes place in the written than in the oral mode. There is no objective measure, but if there were any doubts, the Internet explosion has laid to rest the idea that for the human race at significant 
writing is only a 'minor' form of communication. It is not risky to call writing the single most consequential technology ever invented. The immensity of written record and the knowledge conserved in libraries, data banks, and multilayered information networks make it difficult to imagine an aspect of modern life unaffected by writing. 'Access', the catchword of the knowledge society, means access to written intelligence. Writing not only offers ways of reclaiming the past but is a critical skill for shaping the future. In Stanley Kubrick's 1968 motion picture '2001: A Space Odyssey' a computer equipped with a perfect speech recognition program, which is even able to lip read, threatens to overpower the human crew. This is still science fiction. In contrast, the ability of computers to operate in the written mode, to retrieve, process and organize written language in many ways surpasses unaided human faculties. Mastering the written word in it select ironic guise has become essential.

The commanding relevance of writing for our life notwithstanding, it is anything but easy to provide a clear definition of what writing is. Partly this is because of the multiple meanings of English words and partly because of the long history of writing and its great importance. At least six meanings of 'writing' can be distinguished: (1) a system of recording language employing visible or tactile marks;(2) the activity of putting such a system to use;(3) the result of such activity, a text;(4) the particular form of such a result, a script style such as block letter writing;(5) artistic composition;(6) a professional occupation.

The narratives of the world are numberless. The narrative is first and foremost a prodigious variety of genres, themselves distributed amongst different substances - as though any material were fit to receive man's stories. Able to be carried by articulated language, spoken or written, fixed or moving images, gestures, and the ordered mixture of all these substances; the narrative is present in myth, legend, fable, tale, novella, epic, history, tragedy, drama, comedy, mime, painting (think of Carpaccio's Saint Ursula), stained glass windows, cinema, comics, news item, conversation.

Moreover, under this almost infinite diversity of forms, the narrative is present in every age, in every place, in every society; it begins with the very history of mankind and there nowhere is nor has been a people without narrative. All classes, all human groups, have their narratives, enjoyment of which is very often shared by men with different, even opposing, cultural backgrounds. Caring nothing for the division between good and bad literature, the narrative is international, transhistorical, transcultural: it is simply there, like life itself . (Barthes 1977, p.79).
Digital storytelling is a short form of digital media production that allows everyday people to share aspects of their story. The media used may include the digital equivalent of film techniques (full-motion video with sound), stills, audio-only, or any of the other forms of non-physical media (material that exists only as electronic files as opposed to actual paintings or photographs on paper sounds stored on tape or disc, movies stored on film) which individuals can use to tell a story or present an idea. "Digital storytelling" is a relatively new term which describes the modern practice of everyday people who use digital tools to tell their 'story'. Digital stories often present in compelling and emotionally engaging formats and can be interactive.

The term "digital storytelling" can also cover a range of digital narratives (web-based stories, interactive stories, hypertexts, and narrative computer games); It is sometimes used to refer to film-making in general, and as of late, it has been used to describe advertising and promotion efforts by commercial and non-profit enterprises. One can define digital storytelling as the process by which diverse peoples share their life stories and creative imaginings with others. This newer form of storytelling emerged with the advent of accessible media production techniques, hardware and software, including but not limited to digital cameras, digital voice recorders, iMovie, Windows Movie Maker and Final Cut Express. These new technologies allow individuals to share their stories over the Internet on YouTube, Vimeo, compact discs, podcasts, and other electronic distribution systems (Aswad, M., Rahman, F., Said, I. M., Hamuddin, B., \& Nurchalis, N. F., 2019). How Digital Stories Differ from other Types of videos in today's online environment, the lines between what is and what is not a digital story have become blurred as more videos are shared online. In our experience teaching digital storytelling, many students are confused when asked to define what a digital story is as well as discuss the most important elements of a digital story. In an educational setting, it is reasonable to ask questions of a video to help determine if it might be classified as a digital story.

\section{Method}

The study is carried out in junior high school, and teachers can prepare digital storytelling and show in front of the class. In digital storytelling, there are some narrative texts depend on the teacher serves the matery. A teacher asks students to watch the video about narrative. The video is such animation about the story, after watching the video students are requested to get the point of the story can make again based on their word and describe in the generic structure of the narrative text (orientation, the complication of problem and resolution). 


\section{Discussion}

In the method above, the discussion is based on; teaching narrative text by using digital storytelling in the learning process, motivation, and learning model. I will start by discussing the teaching narrative text by using digital storytelling.

Digital Storytelling" is a relatively new term which describes the modern practice of everyday people who use digital tools to tell their 'story'. Digital stories often present in compelling and emotionally engaging formats and can be interactive. The term "digital storytelling" can also cover a range of digital narratives (web-based stories, interactive stories, hypertexts, and narrative computer games); It is sometimes used to refer to filmmaking in .general, and as of late, it has been used to describe advertising and promotion efforts by commercial and non-profit enterprises. One can define digital storytelling as the process by which diverse peoples share their life stories and creative imaginings with others. This newer form of storytelling emerged with the advent of accessible media production techniques, hardware and software, including but not limited to digital cameras, digital voice recorders, iMovie, Windows Movie Maker and Final Cut Express. These new technologies allow individuals to share their stories over the Internet on YouTube, Vimeo, compact discs, podcasts, and other electronic distribution systems.

\subsection{Uses in Primary and Secondary Education}

For primary grades, the focus is related to what is being taught, a story that will relate to the students. For primary grades, the story is kept under five minutes to retain attention. Vibrant pictures, age-appropriate music and narration are needed. Narration accompanied by subtitles can also help build vocabulary. Content-related digital stories can help upper-elementary, and middleschool students understand abstract or layered concepts. For example, in one 5th grade class, a teacher used digital storytelling to depict the anatomy of the eye and describe its relationship to a camera.

These aspects of digital storytelling, pictures, music, and narration reinforce ideas and appeal to different learning types. Teachers can use it to introduce projects, themes, or any content area, and can also let their students make their own digital stories and then share them. Teachers can create digital stories to help facilitate class discussions, as an anticipatory set for a new topic, or to help students gain a better understanding of more abstract concepts. These stories can become an integral part of any lesson in many subject areas. Students can also create their own digital stories, and the benefits that they can receive from it can be quite plentiful. Through the creation of these stories, students are required to take ownership of the material they are presenting. They have to analyze and synthesize information, as well. All of this supports higher-level thinking. Students can give themselves a voice by expressing their thoughts and ideas.

When students can participate in the multiple steps of designing, creating and presenting their own digital stories, they can build several literacy skills. These include the following: Research skills by finding and analyzing information when documenting the story, writing skills when developing a script, and organization skills by managing the scope of the project within a time constraint. Technology skills can be gained through learning to use a variety of tools, such as digital cameras and multimedia authoring software and presentation skills through the presentation of the story to an audience. Students also gain interview, interpersonal, problem-solving and assessment skills through completing their digital story and learning to receive and give constructive criticism.

\subsection{The 7 Elements of Digital Storytelling}

The Center for Digital Storytelling (CDS) in Berkeley, California is known for developing and disseminating the Seven Elements of Digital Storytelling, which are often cited as a useful starting point as you begin working with digital stories.

Point of View. What is the main point of the story, and what is the perspective of the author?

a) A Dramatic Question. A key question that keeps the viewer's attention and will be answered by the end of the story.

b) Emotional Content. Serious issues that come alive in a personal and powerful way and connects the audience to the story.

c) The Gift of Your Voice. A way to personalize the story to help the audience understand the context.

d) The Power of the Soundtrack. Music or other sounds that support and embellish the story.

e) Economy. Using just enough content to tell the story without overloading the viewer.

f) Pacing. The rhythm of the story and how slowly or quickly it progresses.

The specific requirements of an educational digital story differ slightly from the original Seven Elements for Digital Stories. Working with the Seven Elements that CDS developed, we added a few new items to make them more applicable to the types of digital stories created by students. The modified elements are shown below.

a) The Overall Purpose of the Story 
b) The Narrator's Point of View

c) Dramatic Question or Questions

d) The Choice of Content

e) Clarity of Voice

f) The pacing of the Narrative

g) Use of a Meaningful Audio Soundtrack

h) Quality of the Images, Video \& other Multimedia Elements

i) The economy of the Story Detail

j) Good Grammar and Language Usage

Digital Storytelling can be a powerful educational tool for students at all ages and grade levels who are tasked with creating their own stories. This use of digital storytelling capitalizes on the creative talents of students as they begin to research and tell stories of their own, learn to use the library and the internet to research-rich, in-depth content while analyzing and synthesizing a wide range of information and opinions. Besides, students who participate in the creation of digital stories develop enhanced communication skills by learning to organize their ideas, ask questions, express opinions, and construct narratives. Students who have the opportunity to share their work with their peers may also gain valuable experience in critiquing their own and other students' work, which can promote gains in emotional intelligence, collaboration and social.

Digital Storytelling as an Instructional Tool in Secondary and Post-Secondary Education. For older students, digital storytelling is particularly well suited to the constructivist classroom where these students can construct their meaning through the multi-faceted experience of selecting a story topic, conducting research on the topic, writing a script, collecting images, recording audio narration and using computer-based tools to construct the final story. The result is a multimedia artefact that richly illustrates not only what the student has researched and brought to life, but also what they have learned from the experience. (Ben mayor, 2008) believes that digital storytelling empowers students in a variety of ways, including intellectually, culturally and creatively. After they have designed and created a digital story, new insights are gained through this summative assignment. I ask students to engage in an intellectual reflection that theorizes the story and the process of making it. They are asked to examine how their story (both the narrative and visual texts) fits into more significant concepts, theories and cultural logics we read in the class, and to explain what understanding or insight they draw about their own identities and lives. (p. 190).

Learner Characteristic Teaching Strategy How Digital Storytelling Supports This Technology savvy
Incorporate technology meaningfully into class activities and assignments. Digital stories can be used as class activities and class assignments. Relies on search engines for information Provide assignments that allow students to use search engines, but also critically assess the information they find. Search engines can be used to research digital story topics, locate images, music, video clips that can be included in the story-interested in multimedia Include music, videos, and other media in assignments. Digital stories contain a mix of music, video clips and other media. Creates internet content. Allow students to contribute to websites, blogs, wikis, and create YouTube videos.

Digital stories can be uploaded to blogs, wikis, and other websites, including YouTube. Learns by inductive discovery Provide opportunities for students to be kinesthetic, experiential, hands-on learners. Creating a digital story is a hands-on, experiential process. Learns by trial and error allow students to test their strategies for solving problems and take control of their learning. Digital storytelling allows students to solve the issues and take control of their learning. Short attention span students use technology to move at their own pace. Digital storytelling lets students use technology at their own pace.

Communicates visually allow students to use images, videos and other visual representations in assignments. Digital stories contain a mix of images, video clips and other visual representations. Emotionally open. Encourage personal interaction and opinion sharing. Many of the most powerful digital stories include a personal point of view. Feels pressure to succeed top students' multiple intelligences and emphasize deep learning experiences and critical thinking. Creating a digital story allows students to be creative and critically reflect on what they have learned. Constantly seeks feedback provide opportunities for both positive and negative constructive feedback. Incorporating peer feedback in the digital storytelling process allows students to improve their work.

Digital Storytelling Software for Educators and Students. There are three major categories of software and technology tools that can be used in the creation of digital stories: software programs that can be installed on a desktop or laptop computer, software that can be used through a web-based interface and applications that run on smartphones and tablet computers a Commercial Software. The software that comes preinstalled on many desktop or laptop computers may be a good choice for those just starting with digital storytelling. Windows Movie Maker for Windows and Apple iMovie for Mac are both extremely popular and relatively easy to use. Other software options for desktop and laptop computers include Adobe Premiere 
Elements and even Microsoft PowerPoint. Numerous tutorials and how-to guides are available on the web that demonstrates how to use these tools.

\section{Result}

This study sees in the early stages of its journey that students in junior high school have the ability to improve their writing skill in the narrative text by using digital storytelling. The Analysis of the result somehow in line with numerous past studies which proved as well that the students can be more creative to make a story especially in the narrative text by using digital storytelling. Which makes students can improve their motivation and mastery some aspect in English.

\section{References}

Arizona State University.Garcia, P. \& Rossiter, M. (2010). Digital storytelling as a narrative pedagogy. In D. Gibson \& B. Dodge (Eds.), Proceedings of Society for Information Technology \& Teacher Education

Aswad, M., Rahman, F., Said, I. M., Hamuddin, B., \& Nurchalis, N. F. (2019). A Software to Increase English Learning Outcomes: An Acceleration Model of English as the Second Language. The Asian EFL Journal. 26. (6.2), 157-169.

Ballast, K. (2007). Heart and Voice: A digital storytelling journey.Retrieved from http://www.nwp.org/cs/public/print/resource/2392

Behmer, S., Schmidt, D., \& Schmidt, J. (2006). Everyone has a story to tell: Examining digital storytelling in the classroom.

Benmayor, R. (2008). Digital storytelling as a signature pedagogy for the new humanities. Arts and Humanities in HigherEducation 7(2), 188-204.

Berk, R. A. (2009). Teaching strategies for the net generation. Transformative Dialogues: Teaching \& Learning Journal, 3(2), 1-23.

Boase, K. (2008). Digital storytelling for reflection and engagement: A study of the uses and potential of digital storytelling.Retrieved from https://gjamissen.files.wordpress.com/2013/05/boa $\underline{\text { se assessment.pdf }}$

Cennamo, K., \& Kalk, D. (2005). Real-world instructional design.Belmont, CA: Thompson/Wadsworth Learning.

Clark, D. (2011). ADDIE timeline.Retrieved from:http://www.nwlink.com/ donclark/history_is d/addie.htmlDaniel, J. (2012). Making sense of MOOCs: Musings in a maze of myth, paradox and possibility. Journal of Interactive Media in Education, 3. doi: 10.5334/2012-18

Fletcher, C., \& Cambre, C. (2009). Digital storytelling and implicated scholarship in the classroom. Journal of Canadian Studies, 43(1),109-130.

Foley, L. M. (2013). Digital storytelling in primarygrade classrooms (Unpublished doctoral dissertation),

Nofita, N. S. G., Yudar, R. S., \& Nursafira, M. S. (2019). Exploring Quantity and Diversity of Informal Digital Learning of English (IDLE): A Review of Selected Paper. Utamax: Journal of Ultimate Research and Trends in Education, 1(1), $1-6$.

Safhira, S., \& Hamuddin, B. (2019). Online Interactive Communication via Academic Blogging Activities among Indonesian EFL Students. REiLA: Journal of Research and Innovation in Language, 1(2), 4654.

Susilo, N. (2019). Kahoot Apps in ELT Context: An alternative Learning Strategy. ELSYA: Journal of English Language Studies, 1(1), 11-15. 